\title{
Development of Graphical Oriented Expert System
}

\author{
Konstantin A. Aksyonov ${ }^{1, \text { a) }}$,Olga P. Aksyonova ${ }^{1, \mathrm{~b})}$, Elena K. Aksyonova ${ }^{1, \mathrm{c})}$, \\ Polina E. Ziomkovskaia ${ }^{1, \mathrm{~d})}$, and Wang $\mathrm{Kai}^{2}$ \\ ${ }^{1}$ Yeltsin Ural Federal University, Yekaterinburg, Russia \\ ${ }^{2}$ Institute of Quantitative and Technical Economics, Beijing, China \\ a)Corresponding author:k.a.aksyonov@urfu.ru \\ b)bpsim.dss@gmail.com \\ ${ }^{c}$ wiper99@mail.ru \\ d) polina.ziomk@yandex.ru
}

\begin{abstract}
In this paper the application of expert system apparatus is described of the balanced score card method based on production model of knowledge representation. The proposed approach to creating the Balanced Score Card model automates processes of analyzing the impact of changes in the key indicators and sponsored activities was carried out. Also, the approach enhances estimating the cost of resources necessary to achieve the key indicator taking into accountthe coefficients of confidence in certain dependencies and baseline data.
\end{abstract}

\section{STRATEGY IMPLEMENTATION TOOL - BALANCED SCORECARD}

The degree of success of the implementation of strategic planning and management depends on the ability to adequately determine the compliance of the achieved results with the goals set. This, in turn, is determined by the chosen technology for assessing various parameters of the organization's activities. Such a tool is the BSC method. The Balanced Score Card (BSC) is a powerful tool for managing an organization's strategy, examining its activities in several perspectives, and monitoring performance. The BSC can be applied to monitoring not only the financial performance, but, also, the quality of work with clients, staffs, information technology, production processes, etc. Possible strategic objectives and criteria for evaluating the organization's activities are united into 4 groups: the financial component; client component; component of the internal business processes; component of the staff development and training. The dependence of some goals on others is set by causal relationships.

The BSC is projected onto the entire organization with the subsequent decomposition of strategic goals into the structural units by developing individual tasks within the framework of already developed corporate strategies. The BSC stimulates participants in the process of understanding their place in the organization's development strategy. The main purpose of the BSC is to provide the functions of collecting, systematizing, and analyzing information necessary for making strategic management decisions.

The efficiency of IT companies is assessed through a scorecard. From the point of view of a modern strategic management approach, the Balanced Scorecard $[1,2]$ characteristics of IT companies are the key indicators and are directly used in the decision-making process. Experience of using the BSC in decision support systems is described in [1]. The BSC is a set of activities, strategies, key performance indicators. It is generally described by the following tuple model:

$B S C=\{$ Events, Strategies, Goals, Indicators, Relations $\}$,

The BSC provides the enterprise with only a format for expressing its mission and strategy in specific areas of activity through a system of specific goals and indicators. However, in itself, it does not provide for the collection $[1,2]$, processing of the necessary information, and bringing it to personnel and contractors. Elimination of the above

International Conference of Numerical Analysis and Applied Mathematics ICNAAM 2019

AIP Conf. Proc. 2293, 140005-1-140005-4; https://doi.org/10.1063/5.0027488

Published by AIP Publishing. 978-0-7354-4025-8/\$30.00 
described shortcomings is supposed to be achieved on the basis of information technologies $[3-5,10]$ of the expert and multi agent systems [6-7,9].

One of the most difficult aspects of implementation of the BSC is the definition and analysis of the cause-effect relationships in the system.

As an example, Fig. 1 shows a fragment of the scheme of the main causal relationships for the indicators of one Enterprise.

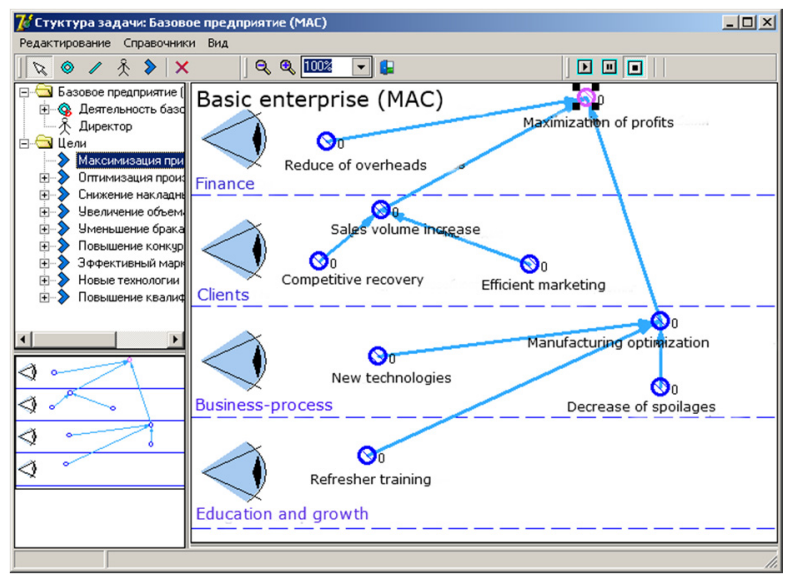

FIGURE 1. Causal diagram of indicators of Enterprise.

\section{REQUIREMENTS FOR A MATHEMATICAL DOMAIN MODEL}

The mathematical model should provide a solution to the following tasks:

1) Assessment of the effect of achieving the selected goal (group of goals);

2) Assessment of the impact of changes in the key indicator (group of key indicators);

3) Assessment of the impact of the implementation of the event (group of events);

4) Assessment of the cost of resources necessary to achieve the goal (group of goals), including the cost of time;

5) Assessment of the costs necessary for the implementation of activities (group of events);

6) Assessment of the costs necessary to change the key indicator (group of indicators), i.e. achievement of certain values of indicators.

7) Assessment of the degree of certainty of decisions made based onthe inference.

\section{APPLICATION TO THE BSC OF THE APPARATUS OF EXPERT SYSTEMS (ES)}

The BSC model can be represented as a production system (PS) [8] with the following structure:

$$
P S=<R p s, \text { Bps, Ips }>\text {, }
$$

where Rps is the current state of goals and key indicators (working memory);

Bps -are the many causal relationships (knowledge base);

Ips - is the output machine (interpreter).

Below, we describe the structure of the BSC elements focused on the apparatus of production systems.

The goal $G_{j}$ is characterized by the objective function $F_{j}$ depending on the indicators $\left\{K P I_{G(j)}\right\}$ and the coefficient of confidence $\left(C F \_G\right)$, the current value, and the planned (desired) value (plan).

$$
G_{j}=\left\langle F_{j}\left(K P I_{1}^{G_{j}}, \ldots, K I_{n}^{G_{j}}\right), C F \_G, \text { curent }, \text { plan }\right\rangle,
$$

The indicator is characterized by the current value, the planned value (plan), the type of indicator (kind), the coefficient of confidence $\left(C F_{-} K P I\right)$, and a sign of a change in the current measure change_takt $=\{$ true, false $\}$

$$
K P I_{d}=\left\langle\text { value, plan, kind }, C F_{-} K P I, \text { change_takt }\right\rangle \text {, }
$$


Indicators can belong to the following types: $<$ base, relation $>$, base -- basic indicators of quantitative properties of resources and mechanisms (for example, the quantity of finished products), relation -- integral and relative indicators formed as convolutions of the basic indicators (described by formulas).

The event is the process. An event can consist of one or many parallel-sequential operations

$$
M_{k}=\left(O p_{1}^{k}, \ldots, O p_{m}^{k}\right),
$$

where $O p_{1}^{k}, \ldots, O p_{m}^{k}$ are the series-parallel operations of the event.

The $O p_{v}$ operation is characterized by the input resources ( $I N^{v} \in$ base - inputs), output resources (OUT $\in$ baseoutputs), means (Mech ${ }^{v} \in$ base), performing input-output conversion (mechanisms), execution time

$$
O p_{v}=\left\langle\left\{N^{v}\right\},\left\{O U T^{v}\right\},\left\{\operatorname{Mech}^{v}\right\}, t^{v}>,\right.
$$

$\{F\}$ defines the entire set of causal relationships and can be given by rules, which translate the values of system indicators from one state to another

$$
\langle\{G\},\{K P I\}\rangle \stackrel{\{\text { Rule }\}}{\longrightarrow}\left\langle\left\{G^{\prime}\right\},\left\{K P I^{\prime}\right\}\right\rangle .
$$

The rules are characterized by a condition, action and events (the set can be degenerate $\left\{M^{r}\right\}=0$ )

$$
\text { Rule }_{r}=<I F_{-} R, C F_{-} \text {if, THEN_R, } C_{-} \text {then, }\left\{M^{r}\right\}, \text { exec_ctakt }>\text {, }
$$

where $I F \quad R$ is the condition of the rule (if), characterized by the coefficient of confidence ( $\left.C F \_i f\right)$;

THEN ${ }_{-} R$ is action of the rule (that), characterized by the coefficient of confidence ( $C F \_$then);

exec_ctakt $=<$ true, false $>$ is the sign of the execution (viewing, marking) of the rule in the current cycle of the output machine.

Calculation of the coefficients of confidence is carried out according to the following formula:

$$
C F(\text { action })=C F(\text { premise }) * C F(\text { rule }) \text {, }
$$

To describe the algorithm, we will use the following operators and variables:

1) curent_rule $=\operatorname{select}(\{$ Rule $\})$ is selection from the knowledge base of the rule for processing;

2) Execute(curent_rule) is the procedure for implementing the current rule;

3) $S T O P$ is the command to stop the output machine.

The following is the output machine algorithm:

1. Step 1. Preliminary stage is setting the initial states of the working memory and setting the markup. For all rules, the label "rule execution in the current cycle" is zero. The clock counter is 0.

$$
\begin{aligned}
& \text { takt_count }=0, \\
& \forall i: \text { Rule }{ }_{i} \text {.exec_ctakt }=\text { false. }
\end{aligned}
$$

2. Step 2. Motion along the graph. The output machine performs a complete enumeration of all the rules by performing the following actions:

a. Selection of the current rule:

$$
\text { curent_rule }=\operatorname{select}(\{\text { Rule }\}):
$$

b. Checking the truth of the parcel. If the premise is correct, then the rule will executed and the changes in the working memory will recorded, and the total resources required for the implementation of the corresponding measures will added to the total cost

$$
\begin{aligned}
& \text { Execute(curent_rule), } \\
& \forall j: \sum_{1}^{m} \sum_{r=r e s} M_{j}(r), M_{j} \in \text { curent_rule; }
\end{aligned}
$$

c. Setting the label of "executing a rule in the current cycle" 


$$
\text { curent_rule.exec_ctakt }=\text { true; }
$$

d. Completion of work with the rule: if there are no more verified rules, go to step 3, otherwise go to step 2.a.

3. Step 3. Check the working memory. Check whether the working memory has changed

$$
\begin{aligned}
& \text { IF }\left(\exists d: K P I_{d} . \text { change_takt }=\text { true }\right), \\
& \text { then }\left(\text { takt_count }=\text { takt_count }+1 ; \forall i: \text { Rule }_{i} . \text { exec_ctakt }=\text { false }\right), \\
& \text { else }(S T O P) .
\end{aligned}
$$

If it has changed, then increase the clock counter by 1 and go to step 2. If it has not, go to the next step.

\section{CONCLUSION}

The proposed approach to creating a BSC model automates processes of analyzing the impact of changes in key indicators and sponsored activities, as well as estimates the cost of resources that are necessary to achieve key indicators, taking into account coefficients of confidence in certain dependencies and initial data. This approach is applied in the development of a graph-oriented expert system of production type.

\section{ACKNOWLEDGMENTS}

This work was supported by Act 211 Government of the Russian Federation, contract № 02.A03.21.0006.

\section{REFERENCES}

1. Scoreboard KPI Performance Management Software. (2018). Example KPIs for Information Technology (IT) : https://kpidashboards.com/kpi/department/information-technology/

2. N.G.Olve, J.Roy, M.Vetter, Evaluation of a company. A Practical guide to using the balanced scorecard, (Publishing house «Wilyame», 2004), 304 p.

3. B.V.Sokolov, A.N.Pavlov, R.M.Yusupov, M.U.Ohtilev, S.A.Potryasaev, "Theoretical and technological foundations of complex objects proactive monitoring management and control", Proceedings of the Symposium Automated Systems and Technologies (Peter the Great St. Petersburg Polytechnic University, Leibniz Universität Hannover, 2015), pp. 103-110.

4. A.Borodin, S.Mirvoda, I.Kulikov, S.Porshnev, "Optimization of memory operations in generalized search trees of PostgreSQL",Proceedings of the International Conference: Beyond Databases, Architectures and Structures, (Poland,2017), pp. 224-232.

5. I.Solovyeva, B.Sokolov, D. Ivanov, "Analysis of position optimization method applicability in supply chain management problem, International Conference "Stability and Control Processes" in Memory of V.I. Zubov (SCP), 2015,pp. 498-500.

6. M.Wooldridge, N.Jennings, D.Kinny, The Gaia Methodology for Agent-Oriented Analysis and Design, Journal of Autonomous Agents and Multi-Agent Systems, 2000, pp. 285-312.

7. K.A. Aksyonov, E.A. Bykov, O.P. Aksyonova, Wang Kai, A.V. Popov, E.F. Smoliy, E.M. Sufrygina, I.A. Spitsina and A.A. Sheklein, "Development of Decision Support and Simulation System BPsim.DSS: Integration of Simulation, expert Situational and Multi-Agent Modeling”, Proceedings of ESM'2009 (ESM European Simulation and Modelling Conference), (United Kingdom, 2009), pp. 256-260.

8. K.A. Aksyonov, E.F. Smoliy, N.V. Goncharova, A.A. Khrenov, A.A. Baronikhina, "Development of Multi Agent Resource Conversion Processes Model and Simulation System", 6th International Conference, Proceedings, Part III. Lecture Notes in Computer Science, Volume 3993,(UK, 2006),pp. 879 - 882. WOS:000238417300114 DOI: 10.1007/11758532_114

9. V.Gorodetsky, L.Cao and P.Mitkas, Agent Mining: The Synergy of Agent and Data Mining, International Journal "IEEE Intelligent Systems", 2009, pp. 64-72.

10. A.Borodin, Y.Kiselev, S.Mirvoda, ,S.Porshnev, "On design of domain-specific query language for the metallurgical industry",Proceedings of the 11th International Conference BDAS: Beyond Databases, Architectures and Structures: Communications in Computer and Information Science,2015,pp. 505-515. 